\title{
Structural, cellular and molecular aspects of immune privilege in the testis
}

\section{Nan Li, Tao Wang and Daishu Han*}

Department of Cell Biology, School of Basic Medicine, Peking Union Medical College, Beijing, China

\section{Edited by:}

Rachel R. Caspi, National Institutes of Health, USA

\section{Reviewed by:}

Kenneth Tung, University of

Virginia, USA

Andreas Meinhardt,

Justus-Liebig-University, Germany

*Correspondence:

Daishu Han, Department of Cell

Biology, Peking Union Medical

College, 5 Dong Dan San Tiao,

Beijing 100005, China.

e-mail:dshan@ibms.pumc.edu.cn
The testis presents a special immunological environment, considering its property of immune privilege that tolerates allo- and auto-antigens. Testicular immune privilege was once believed to be mainly based on the sequestration of antigens from the immune system by the blood-testis barrier in the seminiferous epithelium. Substantial evidence supports the view that the combination of physical structure, testicular cells, and cytokines controls immune responses in the testis to preserve the structural and functional integrity of testicular immune privilege. Both systemic immune tolerance and local immunosuppression help maintain the immune privilege status. Constitutive expression of anti-inflammatory factors in testicular cells is critical for local immunosuppression. However, the testis locally generates an efficient innate immune system against pathogens. Disruption of these mechanisms may lead to orchitis and impair fertility. This review article highlights the current understanding of structural, cellular, and molecular mechanisms underlying the unique immune environment of the testis, particularly its immune privilege status.

Keywords: immune privilege, testis, Sertoli cell

\section{INTRODUCTION}

Immune privilege implies a special status of some sites in a mammalian body, where allo- and auto-antigens are tolerated (Mellor and Munn, 2006). This phenomenon emerged more than a century ago in the eye and the brain of rabbits and rodents during exploration of tumor rejection after transplantation (Simpson, 2006). Later studies revealed various remarkable immune privilege sites including the eye, brain, testis, and pregnant uterus.

The testis is a distinct immune privilege site. The concept of immune privilege in mammals includes two aspects: some tissues induce tolerance after their transplantation to an allogenic recipient and some tissues readily accept foreign cells without the induction of immune rejection. The testis exhibits both two aspects of immune privilege (Fijak and Meinhardt, 2006). A large number of novel proteins are expressed in developing germ cells during spermatogenesis. Therefore, sperm production represents challenges to the immune system since sperms are unique to the body and appear long after the establishment of immune competence. However, the testis tolerates these unique antigens. The testis itself confers protection since auto-antigens induce strong autoimmune responses when they are injected elsewhere in the body (Tung et al., 1981). Initial consideration of the testis as an immune privileged site was substantiated experimentally when allografts placed into the interstitial space of the rat testis survived indefinitely (Head et al., 1983). Transplantation of spermatogonial stem cells into germ cell-depleted testes, even at the interspecies level, can restore spermatogenesis (Brinster, 2002). Similarly, ectopically transplanted allogenic testes under the kidney capsule or subderma of animals resist rejection without systemic immunosuppression in animals (Kuopio et al., 1989; Ma et al., 2004).

The mechanisms of testicular immune privilege have been gradually updated based on the progress of numerous investigations (Fijak et al., 2011). Testicular immune privilege was initially proposed to be attributed to the absence of lymphatic drainage until evidence of the existence of afferent lymphatic vessels in the testis was obtained (Barker and Billingham, 1977). Subsequently, the sequestration of antigens and antibodies from the immune system by the blood-testis barrier (BTB) was believed to play a central role in the maintenance of immune privilege status. A growing body of evidence supports the view that systemic immune tolerance and localized active immunosuppression are involved in the regulation of testicular immune privilege. Therefore, multiple mechanisms, including the special structure of the testis, the immunosuppressive properties of local cells, and paracrine and endocrine cytokines, could control the immune privilege of the testis (Meinhardt etal., 1998; Meinhardt and Hedger, 2011).

\section{STRUCTURAL BASIS OF TESTICULAR IMMUNE PRIVILEGE}

The testis is structurally complex regarding the BTB and the many different cell types it contains. While the testis structure is not fully responsible for the immune privilege, it is involved partially in the maintenance of the special testicular immune environment.

\section{STRUCTURE OF THE TESTIS}

The structure of the adult mammalian testis is highly organized and complex consisting of two distinct regions: the seminiferous tubules and the interstitial spaces between tubules (Figure 1). The testis has two major functions: the generation of sperms (spermatogenesis), and the synthesis of sex steroid hormones (steroidogenesis). Spermatogenesis takes place within the seminiferous tubules, and steroidogenesis is fulfilled by Leydig cells located in the interstitial spaces. The sex steroid hormones, mainly testosterone in the testis, are critical for normal spermatogenesis. 


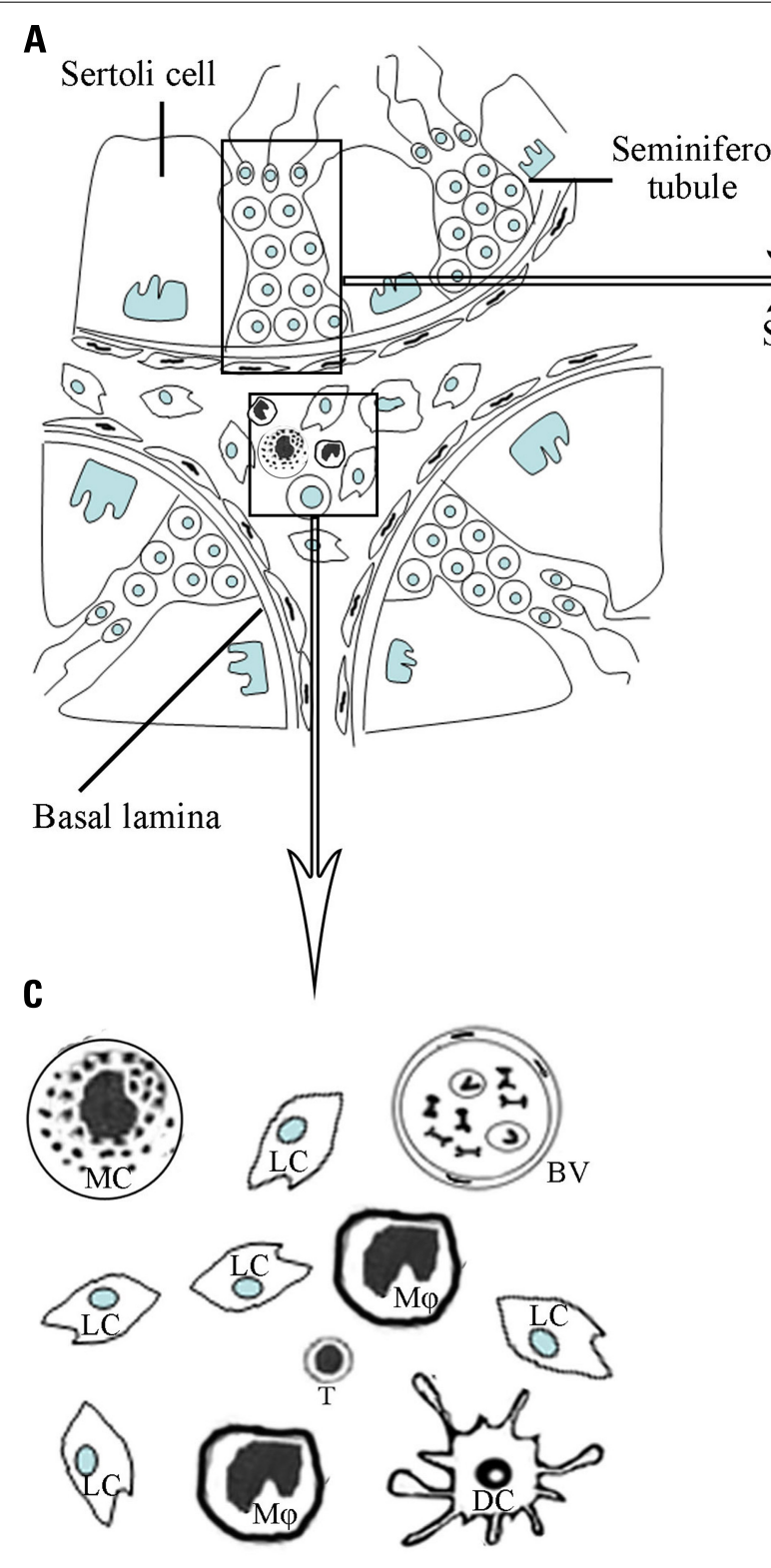

A

C

FIGURE 1 | A schematic drawing of micrographs of mammalian testicular structure and cells. (A) The testis consists of two distinct regions, namely, seminiferous tubules and interstitial compartments. (B) Within the seminiferous tubules, the different stages of developing germ cells are in intimate association with Sertoli cells, forming the seminiferous epithelium. The blood-testis barrier is formed by junctions
B

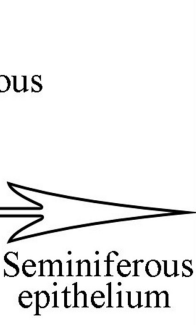

Meiotic
division 2

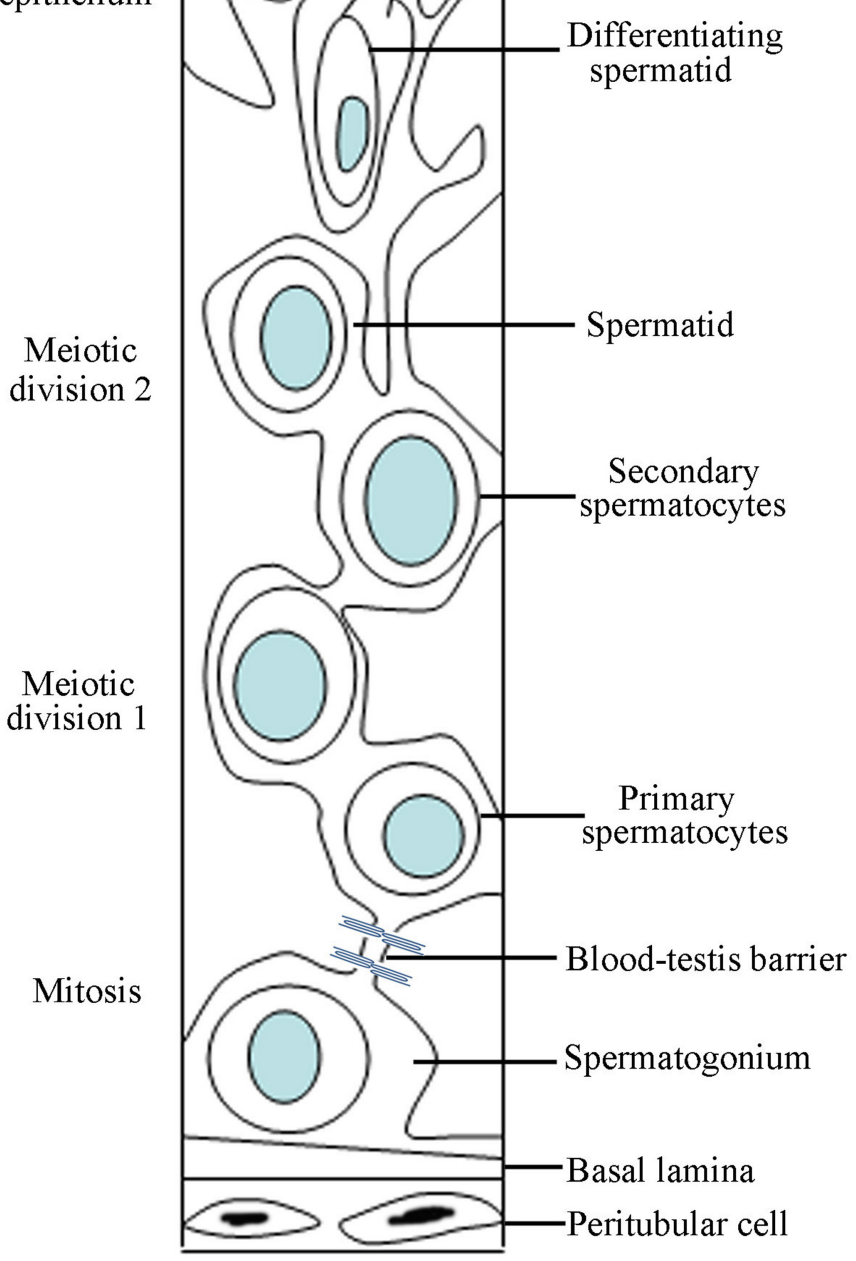

between neighboring Sertoli cells near the basement membrane. (C) Amplification of the interstitial compartment shows cell types. Leydig cells (Lc) are majority of the interstitial cells. There are various types of immune cells including mainly macrophages $(\mathrm{M} \varphi)$ and minor dendritic cells (DC), T lymphocytes (T) and mast cells (MC). The blood vessels (BV) exist in the interstitial compartment.
The seminiferous tubules, which are highly coiled, originate and terminate at the rete testis. The tubules are surrounded by myoid peritubular cells (MPCs), which, together with Sertoli cells (SCs), secrete components of the basement membranes that enclose the seminiferous epithelium. Columnar SCs extend from the basal lamina to the lumen of the tubules. These SCs are responsible for physical support of the germ cells, providing them with essential nutrients and growth factors.
Besides Leydig cells in the testicular interstitial spaces, there are also blood and lymphatic vessels, as well as various immune cells including macrophages, mast cells, dendritic cells (DCs), and lymphocytes (Figure 1). The interstitium represents the first line of testicular defense against pathogens from the bloodstream. The rete testis, which is a transition zone between the testis and the epididymitis, is the exit of the testis. The BTB is terminated in the rete testis and spermatozoa are no longer protected 
from autoimmune attacks in the rete testis. Thus, certain forms of autoimmune orchitis are primarily observed in the rete testis (Itoh et al., 2005).

\section{BLOOD-TESTIS BARRIER}

The BTB is created near the basement membrane by various junctions including tight junctions (TJs), basal ectoplasanic specializations, gap junctions, and demosome-like junctions between two adjacent SCs (Su etal., 2011). The BTB is anatomically much more complex than other blood-tissue barriers, such as the blood-brain and blood-retina barriers, which are constructed exclusively of TJs between endothelial cells. Moreover, the BTB can be comprised of three components, namely anatomical, physiological, and immunological barriers (Mital et al., 2011). The junctions that restrict passage of molecules and cells into or out of the BTB form the anatomical barrier. The physiological barrier comprises transporters that regulate the passage of substances, creating a microenvironment for spermatogenesis. The immunological barrier limits the access of systemic immunity and sequesters the majority of the auto-antigenic germ cells. A functional BTB relies on the complex interaction between the three components.

The immune privilege status of the testis was initially believed to be mainly based on the sequestration of antigens and antibodies by the BTB. This view has been challenged by the observation that the testicular interstitial spaces, which are located outside the BTB, are also immune-privileged (Setchell, 1990). Moreover, although the BTB sequesters most of the auto-antigenic germ cells in the adluminal compartment of the testis, preleptotene spermatocytes and spermatogonia located outside the BTB also express antigenic molecules (Yule et al., 1988). Therefore, the BTB is partially responsible for the testicular immune privilege. A growing body of evidence shows that the actively immunosuppressive mechanisms in the testis play important roles in maintaining the testicular immune privilege status (Meinhardt and Hedger, 2011). Thus, both the BTB and local immunoregulatory mechanisms contribute to the testicular immune privilege.

\section{TESTICULAR IMMUNE PRIVILEGE IN DIFFERENT SPECIES}

The testicular immune privilege depends on the species. Allografts and xenografts can survive in the testes of some species, such as rat and mouse (Head and Billingham, 1985). By contrast, similar studies on ram and monkey have not been successful (Setchell et al., 1995). Moreover, the testes of some species do not have privilege properties as donor tissues. Mouse testis allografts under the kidney capsule survive long time (Bellgrau et al., 1995), but adult rat testes grafted to the kidney were rejected (Statter et al., 1988). These differences suggest that the factors controlling testicular immune privilege are variable among species.

An intact testis is not necessary for the immune privilege. In fact, SCs display an inherent immunosuppressive role that supports the survival of cells from other tissues, such as pancreatic islet cells, when they were co-transplanted (Selawry and Cameron, 1993; Suarez-Pinzon et al., 2000). While these previous studies support that the genetic elements play roles in the maintenance of testicular immune privilege, some common mechanisms underlying the immune privilege of the testis should be existed in different species. Notably, the immune privilege of the testis does not mean the absence of immune responses in this tissue, rather, such responses are only reduced.

\section{CELLULAR MECHANISMS OF TESTICULAR IMMUNE PRIVILEGE}

The testis is composed of various cell types including immune cells and testis-specific cells (Figure 1). Most types of immune cells, which contain predominantly macrophages, can be found in the interstitial spaces and are important for maintaining the special immunological environment of the testis. Tissue-specific cell types include the somatic cells: SCs, Leydig cells, and MPCs, as well as the different stages of developing germ cells. A growing body of evidence indicates that the testis-specific cells exhibit immunological functions, thus contributing to the testicular immune privilege.

\section{IMMUNE CELLS IN THE TESTIS}

While the testis is a remarkable immune privilege site, it is well connected to afferent lymph nodes. Therefore, the testis has most types of immune cells, including macrophages, T lymphocytes, DCs, and mast cells. These immune cells are important in the maintenance of the special testicular immune environment.

\section{Macrophages}

Macrophages represent a major population among immune cells in the interstitial space of the testis. Macrophages represent about $20-25 \%$ of the interstitial cells of rats under physiological conditions (Hedger, 2002). At least two subsets of macrophages can be discerned. One of them can be defined by the expression of a surface antigen that is recognized by antibody ED2, while the other subset expresses a lysosomal glycoprotein recognized by antibody ED1. ED2 ${ }^{+}$macrophages, which are considered to be resident cells in the testis, represent the majority $(\sim 80 \%)$ of testicular macrophages. ED1 ${ }^{+}$macrophages, which presumably derive from circulating monocytes/macrophages that have only recently arrived in the testis, represent a minor $(\sim 20 \%)$ proportion of all testicular macrophages. The balance between these two macrophage subsets in rats can be disrupted under orchitis conditions (Breucker, 1978; Rival et al., 2008). Clinical studies have shown that macrophage numbers are increased in the testes of patients with aspermatogenesis of different etiologies (Frungieri et al., 2002a). These observations suggest that testicular macrophages associate with the immune homeostasis in the testis and normal spermatogenesis.

Aside from the common features of macrophages in other organs, testicular macrophages display tissue-specific functions. Testicular macrophages, which have close physical interaction with Leydig cells, show important roles in the development and steroidogenesis of Leydig cells in adult rats (Gaytan et al., 1994; Hutson, 2006). Moreover, testicular macrophages also influence SC functions and spermatogenesis by producing soluble factors (Cohen etal., 1999). As a major immune cell population, the macrophages in the testis are believed to be critical in maintaining the testicular immune environment, particularly its immune privilege properties. Testicular macrophages display a reduced capacity for producing inflammatory factors compared with macrophages 
from other tissues (Kern et al., 1995) and exhibit immunosuppressive properties (Kern and Maddocks, 1995), which should contribute to the maintenance of testicular immune privilege.

However, the two types of testicular macrophages exhibit different immune properties. ED2 ${ }^{+}$resident macrophages, which are believed to participate to maintain the immune privilege status in the testis, do not initiate inflammatory responses in LPSchallenged rats (Gerdprasert et al., 2002b). In contrast, ED1 ${ }^{+}$ macrophages migrate into the testis during acute and chronic inflammation and prominently initiate the inflammatory process by releasing inflammatory cytokines with the potential to overcome the immune privilege and mount innate immunity to defense pathogens (Gerdprasert et al., 2002a; Rival et al., 2008). LPS-induced acute inflammation results in only a temporary influx of new $\mathrm{ED}^{+}$macrophages, which can be resolved within a day or two (Gerdprasert et al., 2002a). In contrast, the increased number of $\mathrm{ED}^{+}{ }^{+}$cells is maintained for long periods of time during chronic inflammation, such as autoimmune orchitis (Theas et al., 2008). These observations give rise to several important questions (Fijak and Meinhardt, 2006). What factors are responsible for the recruitment and resolution of $\mathrm{ED}^{+}$macrophages under acute inflammatory conditions? What causes the persistent elevated macrophage numbers in the testis with autoimmune orchitis? What factors regulate the balance of $\mathrm{ED}^{+}$inflammatory cells and $\mathrm{ED}_{2}{ }^{+}$resident immunosuppressive macrophages in the testis under physiologic conditions? The roles of $\mathrm{ED}^{+}$ macrophages in the pathogenesis of autoimmune orchitis remain largely unclear.

\section{Dendritic cells}

Dendritic cells are bone marrow-derived specialized antigenpresenting cells (APCs), and induce activation and differentiation of lymphocytes in response to antigens. DCs not only activate lymphocyte responses to allo-antigens but also inhibit autoimmune responses by tolerating $\mathrm{T}$ cells to auto-antigens, thereby mounting immune responses against invading pathogens and minimizing the responses to auto-antigens (Banchereau and Steinman, 1998). DCs represent a minor population $\left(\sim 1 \times 10^{5}\right)$ of the interstitial cells in normal rat testis (Sanchez et al., 2006), numbering about one-tenth of the macrophages (Meinhardt et al., 1998). Since DCs are the most important immunoregulatory cell types, they could play roles in regulating testicular immune responses. However, testicular DCs have not been paid enough attentions because their minor ratio in the testis. The number of DCs in the testis significantly increases in experimental autoimmune orchitis (EAO) models (Sanchez et al., 2006), suggesting that DCs may participate in the development of testicular autoimmunity. The mechanisms underlying the functions of DCs in EAO remain elusive. Various heat shock proteins (HSPs), including HSP60 and HSP70, which are abundant in male germ cells, have recently been characterized as testicular auto-antigens in EAO (Fijak et al., 2005). They may initiate the testicular DC-mediated activation of auto-reactive lymphocytes. HSP70 has been reported to promote APC function and converts $\mathrm{T}$ cell tolerance to autoimmunity in vivo (Millar et al., 2003). Therefore, the immature DCs, which normally participate in maintaining immune privilege, can be hypothesized to mature by sensing self-antigens, such as HSPs, and mature
DCs may convert immune privilege by the local activation and expansion of auto-reactive T cells (Fijak et al., 2011). The role of DCs in regulating the testis immunity is worthy of further investigation.

\section{Lymphocytes}

The testis has afferent lymphatic vessels (Barker and Billingham, 1977). Approximately $15 \%$ of the testicular immune cells in adult rat are T cells with predominant $\mathrm{CD} 8^{+}$cells, whereas $\mathrm{B}$ cells are not found in the normal testis (Hedger and Meinhardt, 2000). Testicular lymphocyte numbers are increased in EAO models (Lustig etal., 1993) and infertile patients with sperm autoimmunity (el-Demiry et al., 1987). In EAO, CD ${ }^{+}$and $\mathrm{CD}^{+}$cell numbers dramatically increase at the onset of disease. $\mathrm{CD} 4^{+}$cell numbers decrease and $\mathrm{CD}^{+}$cells remain consistent during disease progression. These data suggest that $\mathrm{CD}^{+}$cells may be involved in the initiation of the chronic phage of EAO. Interestingly, the two subsets of lymphocytes contain regulatory T cells (Tregs), which inhibit antigen-specific immune responses (Andre et al., 2009).

Studies on pancreatic islet cell allografts in mouse testes shown that activated T cells are destroyed and graft antigen-specific Tregs are produced when they enter the testis environment (Dai et al., 2005; Nasr et al., 2005). CD $4^{+} \mathrm{CD} 25^{+}$Tregs are critical for peripheral tolerance. Tregs may control immune privilege within organs by preventing autoimmunity induction in regions where antigenspecific Tregs continuously encounter tissue antigens (Samy et al., 2005). This mechanism controls tolerogenic versus autoimmune response to sperm in vasectomy (Wheeler et al., 2011). Tregs are found within the testicular interstitium under physiological conditions (Jacobo et al., 2009) and may contribute to the testicular immune privilege.

\section{Mast cells}

Mast cells are another immune cell population with considerable numbers in the testis. Mast cells in mammalian testis regulate steroidogenesis by Leydig cells (Aguilar et al., 1995). The increased mast cell numbers in the testis is associated with male infertility (Hussein et al., 2005). Mast cells secret serine protease tryptase, which promotes the proliferation of fibroblasts and synthesis of collagen (Abe et al., 1998), leading to fibrosis, sclerosis, thickening hyalinization of tissues, all of which are the features frequently found in the testis of infertile patients (Apa et al., 2002). Fibrosis results in granuloma formation. Mast cells involve in the granuloma formation in the testis through proteinase-activated receptor-2 (PAR2) activation. PAR2 is localized to the MPCs, macrophages, and acrosomes of spermatids in rat testis, and involved in the development of testicular inflammation (Iosub et al., 2006). PAR2 expression in EAO models is upregulated and associated with granuloma formation. Mast cells are 10fold higher in number and distributed around granulomas in the testis of EAO compared to normal animals. The mast cells release tryptases into the interstitial spaces in EAO models, thus activating PAR2 to induce cell proliferation and cytokine production. Upregulation of monocyte chemoattractant protein-1 (MCP-1) could, at least in part, be responsible for the massive infiltration of macrophages into the testis. Similarly, evidence shows that testicular fibrosis is related to PAR2 activation by mast cells 
(Frungieri etal., 2002b). Most of the studies on the mast cells focus on their role in regulating testicular inflammation. The role of mast cells in testicular immune privilege remains unknown. The relatively low number and restricted distribution of mast cells in the normal testis are believed to be one of mechanisms underlying immune privilege. Prevention of mast cell activation may be a strategy to maintain the immune privilege status of the testis.

\section{TISSUE-SPECIFIC CELLS OF THE TESTIS}

Aside from the immune cells, growing evidence shows that the testis tissue-specific cells exhibit immunological functions and contribute to the maintenance of the testicular immune environment.

\section{Leydig cells}

Leydig cells represent the majority of the cell population in the interstitial compartment of the testis. Leydig cells are critical endocrine cells that produce androgens for both the seminiferous tubule compartment to regulate spermatogenesis and peripheral circulation to extra-testicular androgen-target organs (Diemer et al., 2003). Several studies have shown that rat Leydig cells exhibit high antiviral activities in response to viral infections (Dejucq et al., 1998; Melaine et al., 2003), whereas human Leydig cells display relatively weak antiviral abilities (Le Tortorec et al., 2008). The mechanisms of Leydig cell-initiated antiviral responses remain elusive.

Leydig cells may also regulate testicular immunity through affecting the immune cell functions. It has been known that Leydig cells regulate the expansion of testicular macrophages and lymphocyte numbers in the testis (Raburn et al., 1993; Hedger and Meinhardt, 2000). Androgens have immunosuppressive roles, contributing to the immunological differences between sexes (Cutolo et al., 2004). A blockade of androgen production in Leydig cell rapidly rejects intratesticular allografts, suggesting the role of androgens in regulating immune privilege (Head and Billingham, 1985). The intratesticular testosterone concentration is 10-fold higher than the serum concentration far greater than necessary for the maintenance of normal spermatogenesis (Jarow et al., 2005). The high local testosterone concentration is likely involved in the maintenance of the testicular immune privilege. Testosterones seem to play immunosuppressive functions by regulating the balance between pro- and anti-inflammatory cytokine expression in SCs, Leydig cells, and MPCs, but they should not directly affect testicular leukocytes since androgen receptors have not been found in testicular immune cells. The role of testosterones in regulating testicular immune responses is worthwhile to be further investigated.

\section{Myoid peritubular cells}

Myoid peritubular cells surround the seminiferous tubules, and build a wall supporting the integrity of the tubules (Figure 1). MPCs contain contractile elements that help transport the immotile spermatozoa into the epididymis (Maekawa et al., 1996). MPCs secrete the components of the basal lamina that enclose the contents of the seminiferous epithelium. Several layers of MPCs build the walls of the tubules in human males, whereas only one layer of MPCs in rodents. The functions of MPCs in regulating spermatogenesis are largely unexplored. Previous studies have shown that MPCs can directly, or more likely indirectly, regulate spermatogenesis and testis development via secreted factors (Verhoeven et al., 2000). A recent study indicated that MPCs express androgen receptors and mediate androgen actions on fetal SC proliferation (Scott et al., 2007). Based on their localization and structure, MPCs are believed to participate in the maintenance of the testicular immune environment. A role of MPCs in testicular inflammation has emerged, especially in EAO (Schuppe and Meinhardt, 2005). MPCs release a number of cytokines, including transforming growth factor $\beta$-2 (TGF $\beta$-2), MCP-1, and leukemia inhibitory factor. MCP-1 should, at least in part, account for the recruitment of inflammatory monocytes and/or macrophages to inflame the testis. Human MPCs express TNF- $\alpha$ receptors 1 and 2 , which mediate the expression of other inflammatory molecules, including IL-6 and COX-2 (Schell etal., 2008). The roles of MPCs in the testicular inflammatory responses must be further clarified.

\section{Sertoli cells}

Sertoli cells are only somatic cells within the seminiferous tubules and acquire a columnar sharp extending from the basal lamina toward the lumen of the tubules (Figure 1). SCs constitute the main structural element of the seminiferous epithelium and are responsible for the physical support of germ cells, aside from providing essential nutrients and growth factors. Moreover, immune activities of SCs in the testis are emerging.

Sertoli cells were recognized to have immunosuppressive activities two decades ago (Wyatt et al., 1988; De Cesaris et al., 1992). They are able to provide an immunoprotective environment for some allografts and xenografts in co-transplantation experiments (Sanberg et al., 1996; Suarez-Pinzon et al., 2000). This immunoprotective environment can not be due to the physical barrier formed by SCs in the testis, rather, it seems to be provided by the inherent properties of the cells. Factors secreted by SCs, and the molecules expressed on their surfaces are most likely participated in the immunoprotection of SCs. Molecule mechanisms underlying the immunological functions of SCs will be discussed in late sections of this review.

More than half of all developing germ cells undergo apoptosis during spermatogenesis, and the cytoplasmic portions of elongated spermatids are shed and form residual bodies in the last stage of spermatogenesis. Phagocyte removal of the apoptotic germ cells and residual bodies by SCs are critical for healthy germ cells to proceed through spermatogenesis. The importance of removal of the apoptotic cells and residual bodies for normal spermatogenesis can be hypothesized as follows (Nakanishi and Shiratsuchi, 2004): (1) elimination of apoptotic cells provides appropriate space in the seminiferous epithelium for normal spermatogenesis; (2) apoptotic cells and residual bodies must be removed prior to secondary necrosis that may release noxious contents for healthy cells; and (3) the uptake of residual bodies and apoptosis cells endows SCs into producing factors necessary for spermatogenesis. However, direct evidence showing the meaning of phagocytic removal of apoptotic cells and residual bodies by SCs is still missing.

Phagocytosis is a fundamental cellular process that serves multiple functions in immunity (Greenberg and Grinstein, 2002). 
The significance of phagocytic removal of apoptotic germ cells by SCs in maintaining testicular immune environment has not been revealed. Growing evidence shows that endogenous Toll-like receptor (TLR) ligands released from damaged tissues and necrotic cells can induce non-infectious inflammation through TLR activation (Piccinini and Midwood, 2010). Numerous endogenous TLR ligands high-mobility group box1 (HMGB1) and different HSPs have been identified (Vabulas et al., 2001; Curtin et al., 2009; Wheeler et al., 2009). HMGB1 and HSPs are abundantly expressed in male germ cells (Biggiogera et al., 1996; Zetterstrom et al., 2006). Therefore, one can hypothesize that necrotic germ cells and broken down residual bodies under some pathological conditions may release endogenous TLR ligands, inducing non-infectious inflammation. This hypothesis is agreement with the previous observations that physical trauma and chemical noxae, which induce germ cell apoptosis, associate with chronic testicular orchitis (Schuppe et al., 2008). A recent study showed that an impaired removal of apoptotic germ cells induce non-infectious testicular inflammation, thus favoring autoimmunity in the testis (Schuppe etal., 2008; Pelletier etal., 2009). The meaning of phagocytic removal of apoptotic germ cells by SCs in maintaining testicular immune environment should be an interesting topic to be investigated.

\section{Germ cells}

Sperm production is a major function of the testis, and developing germ cells represent the majority of testicular cells. However, the roles of germ cells in regulating testicular immune environment have yet to be extensively investigated. Previous studies demonstrated that male germ cells secrete various inflammatory cytokines, including IL- $1 \alpha$ (Haugen et al., 1994) and TNF- $\alpha$ (De etal., 1993). Moreover, spermatogonia produce antiviral proteins in response to interferon (IFN) $-\alpha$ and IFN- $\gamma$ (Melaine et al., 2003). In physiology, these cytokines may play roles in controlling the efficiency of spermatogenesis by inhibiting germ cell apoptosis (Pentikainen et al., 2001). In pathology, inflammatory cytokines are up-regulated in the testis of EAO models and impair spermatogenesis through stimulation of inflammation and induction of germ cell apoptosis (Rival et al., 2006; Theas et al., 2008).

Most intriguingly, Fas ligand (FasL) is abundantly expressed in the meiotic and post-meiotic germ cells (D'Alessio et al., 2001). FasL-expressing cells may contribute to immune privilege by inducing apoptosis of Fas-bearing lymphocytes (Suda et al., 1993). Recent studies have revealed that some stages of spermatogenic cells express TLRs, which will be discussed in a late section of this paper. The role of male germ cells in maintaining the special testicular immune environment is emerging, and worthy of further investigation.

\section{MOLECULAR ASPECTS OF TESTICULAR IMMUNE PRIVILEGE}

The testicular cells express and secret numerous immunoregulatory molecules that play important roles in regulating immune responses in the testis (Figure 2). Various immunosuppressive molecules, such as androgens, programmed death ligand-1 (PD-L1), FasL, growth arrest-specific gene product 6 (Gas6), and protein $\mathrm{S}$ (ProS) are produced by testicular cells. To overcome immune privilege, the testis must mount appropriate local innate response against invading pathogens. TLRs in testicular cells play important roles in initiating testicular innate immune responses.

\section{EFFECT OF HORMONES ON THE TESTICULAR IMMUNE RESPONSES}

Macrophages and Leydig cells represent major immune and endocrine cells in the interstitial spaces, these two cell populations regulate each other's development (Hedger, 2002). Luteinizing hormone may control macrophage expansion in the testis during puberty and maintenance of macrophages in the adult testis by acting on Leydig cells (Raburn et al., 1993). Evidence shows that follicle-stimulating hormone regulates maturation of testicular macrophages via SCs (Duckett et al., 1997). Moreover, the testicular endocrine environment can affect other type of immune cells in the testis (Hedger and Meinhardt, 2000). The immune cells in the testis should be regulated by the function of a mature testis, rather than the direct effects of the hormones on the immune cells that lack hormone receptors (Meinhardt and Hedger, 2011).

Production of androgens (mainly testosterone) is a major function of Leydig cells. Androgens exhibit immunosuppressive activities that contribute to different immune responses between the sexes (Cutolo et al., 2004). Testosterone reduces TLR4 expression in macrophages (Rettew et al., 2008). Administration of testosterone suppresses autoimmune diseases (Cutolo, 2009; Gold and Voskuhl, 2009). Accordingly, gonadotropin-releasing hormone antagonists significantly reduce the percentage of Treg cells, and increase the proportion of NK cells in human males (Page et al., 2006). These data suggest that androgens play roles in maintaining the balance between autoimmunity and tolerance. Substantial evidence of the link between androgens and testicular immune privilege was found in investigations using mice conditional knockout androgen receptors in SCs. SC-specific deletion of the androgen receptor in mice disrupts testicular immune privilege (Meng etal., 2011), possibly because androgens regulate SC TJs (McCabe et al., 2010). In agreement with these the data above, an earlier study indicated that androgens regulate the permeability of the BTB by regulating the expression of a SC TJ protein, CLDN3 (Meng etal., 2005). Taken together, androgens play critical roles in maintaining the integrity of testicular immune privilege by regulating local microenvironments.

\section{Fas/FasL SYSTEM}

FasL-induced lymphocyte apoptosis was once thought as a critical mechanism underlying the testicular immune privilege. This concept was contradicted by different studies. FasL suppresses immune responses by inducing apoptosis of Fas-bearing activated lymphocytes (Dhein et al., 1995). The testis is a major source of FasL mRNA in rodents (Suda et al., 1993), and the Fas/FasL system was demonstrated to be important in the maintenance of testicular immune privilege based on observations that SCs expressing FasL induce apoptosis of Fas-bearing lymphocytes (Bellgrau et al., 1995; Takeda et al., 1998; Figure 2). This conclusion was challenged by other studies. Genetically modified islets expressing FasL did not protect the islets from immune rejection (Allison et al., 1997). Neutralizing antibodies against FasL did not significantly reduce 


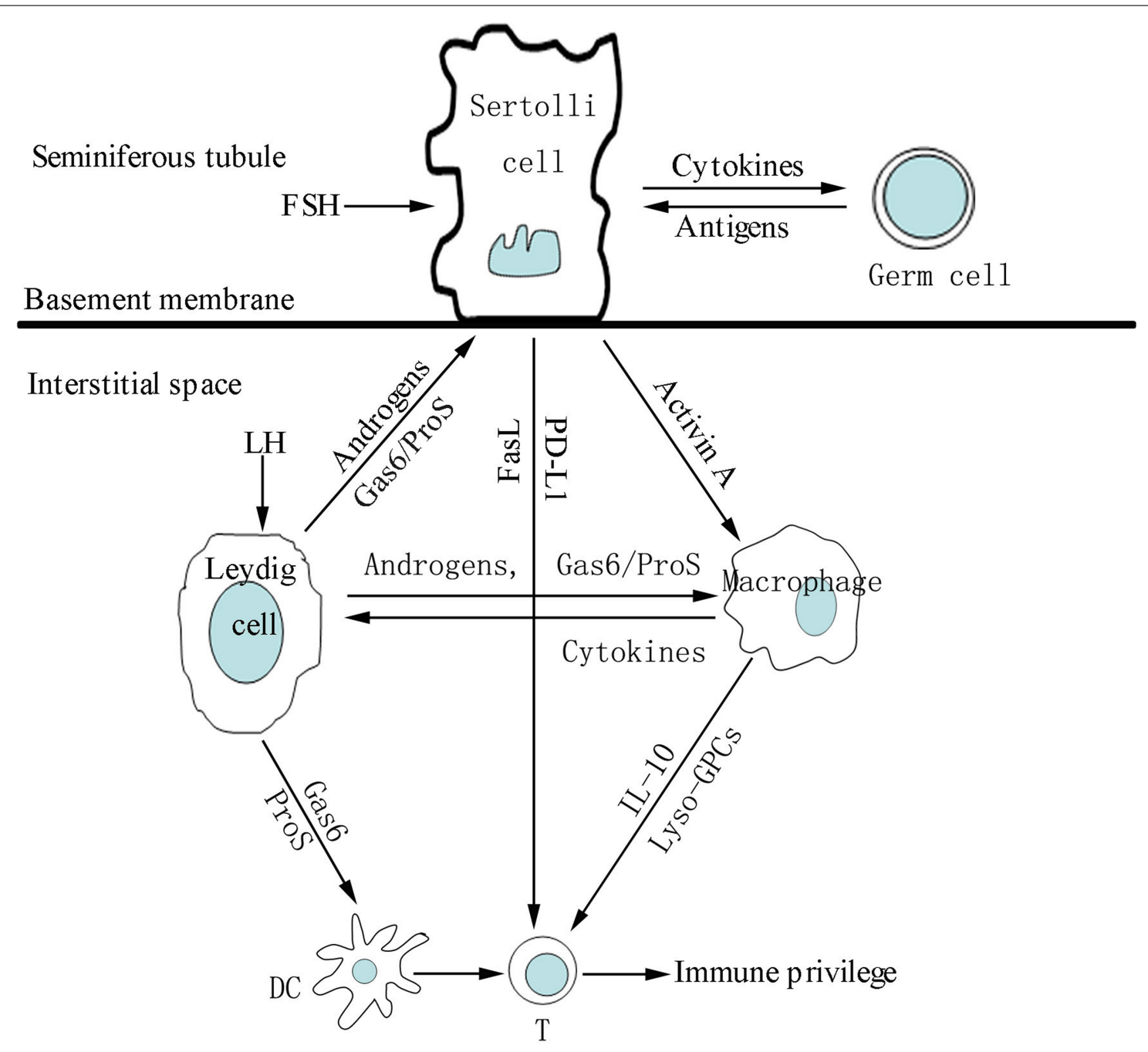

FIGURE 2 | A schematic drawing illustrating intercellular communication via paracrine immunosuppressive molecules that favor immune privilege in the testis. Under the influence of follicle-stimulating hormone (FSH), androgens and germ cell antigens, Sertoli cells secrete immunosuppressive molecules that inhibit inflammatory responses of macrophages and T lymphocytes (T) in the interstitial compartments. Sertoli, Leydig cells and macrophages regulate activities of the other immune cells including dendritic cells (DC), T and mast cells (MC) via paracrine immunosuppressive molecules, favoring testicular immune privilege property. the survival of islets in non-obese diabetic mice that received co-grafts of SCs and islets (Korbutt et al., 2000).

In fact, convincing evidence showed that testicular FasL is expressed not in SCs but in meiotic and post-meiotic germ cells (D'Alessio et al., 2001). However, it remains to be clarified whether the germ cells expressing FasL contribute to the immune privileged status within the seminiferous tubules. Discrepant distribution of FasL as indicated in these previous studies might be caused by cell contamination and usage of non-specific antibodies. The involvement of Fas/FasL in the immunosuppressive properties of SCs should be reconsidered.

\section{LOCAL IMMUNOSUPPRESSIVE MILIEU}

While the role of Fas/FasL system in maintaining the testicular immune privilege has been in doubt, other immunosuppressive molecules have been demonstrated to play roles in suppressing immune responses in the testis. A recent study shows that lyso-glycerophosphatidylcholines (lyso-GPCs) in interstitial fluid inhibit $\mathrm{T}$ cell activity, contributing to testicular immunosuppression (Foulds et al., 2008). However, the mechanisms underlying the lyso-GPC-mediated immune suppression remain unclear. Programmed death receptor-1 (PD-1) is a transmembrane protein, and PD-L1 (also named B7-H1) is a functional ligand of PD-1. PD-1 is expressed in T cells, and its activation by PD-L1 mediates $\mathrm{T}$ cell tolerance (Keir et al., 2006). A recent study demonstrated that PD-L1 is constitutively expressed in the testis and contributes to the long-term survival of islet allografts transplanted in the testis, suggesting that the PD-1/PD-L1 system may contribute to testicular immune privilege (Cheng et al., 2009).

Another attention deserves to be paid to the role of Gas6/ProSTAM system in maintaining testicular immune environment. TAM receptors are the latest identified subfamily of receptor 
tyrosine kinases, which include three members, namely, Tyro3, Axl and Mer (TAM; Hafizi and Dahlback, 2006). Two close relative vitamin K-dependent proteins, the product of Gas6 and ProS (a blood anticoagulant cofactor), are biological ligands of TAM receptors (Hafizi and Dahlback, 2006). TAM triple knockout mice are male infertile due to progressive loss of germ cells (Lu et al., 1999; Chen et al., 2009). Gene targeting mutation studies have shown that TAM receptors are essential regulators of the immune homeostasis by regulating negatively TLR-initiated innate immune responses in DCs and macrophages (Rothlin et al., 2007; Lemke and Rothlin, 2008). We previously demonstrated that TAM receptors are abundantly expressed in mouse SCs and Leydig cells, whereas Gas6 and ProS are prominently expressed in Leydig cells (Wang et al., 2005). We also provided recently evidence that TAM signaling suppresses TLR-initiated testicular innate immune responses in SCs and Leydig cells (Sun et al., 2010; Shang etal., 2011). Based on these findings, we speculate that the Gas6/TAM system may be critical in regulating the immune privileged status of the testis. It is worthwhile to investigate this possibility.

\section{TLR-INITIATED TESTICULAR INNATE IMMUNE RESPONSES}

An immune privileged status does not indicate that the site has no effective immune response. Actually, the testis tolerates invading antigens. TLR-mediated innate immune responses in testicular cells play a critical role in the protection of the testis from infections.

Toll-like receptors are pattern recognition receptors that recognize pathogen-associated molecular patterns (PAMPs). The activation of TLRs by PAMPs represents one of the most important mechanisms of immune responses against pathogens (Takeda and Akira, 2005). TLRs can be also recognized and activated by endogenous ligands that can be released from damaged tissues and necrotic cells, which are termed damage-associated molecular patterns (DAMPs; Seong and Matzinger, 2004). The expression and significance of TLRs in the testicular functions have recently been recognized (Hedger, 2011). Various TLRs are expressed in the testis of different species including humans (Fujita et al., 2011) and murines (Bhushan et al., 2008). Most studies on TLR functions in the testis have been performed using murine models. Recent studies demonstrated that mouse SCs express functional TLR2 to TLR6 (Riccioli et al., 2006; Starace et al., 2008; Wu et al., 2008), which were confirmed in rat SCs (Bhushan etal., 2008; Winnall et al., 2011). Using isolated testicular cells, we also demonstrated in vitro that TLR3 and TLR4 in mouse Leydig cells, and TLR3 in spermatogenic cells trigger innate immunity in response to ligand stimulation (Shang et al., 2011; Tao et al., 2012). TLR2 and TLR4 were observed in human sperms, and responded to bacterial endotoxins (Fujita et al., 2011). The observations imply that TLRs in non-immune testicular cells may play important roles for the testis to mount appropriate local innate immune responses to invading microbial pathogens. Notably, SCs are relatively less sensitive to ultra-pure LPS or Poly(I:C) compared with macrophages based on the expression levels of inflammatory cytokines, although both cell types express comparable levels of TLR3 and TLR4. Inhibitory effect of Gas6/ProS-TAM system on TLR signaling in both SCs and Leydig cells should be responsible, at least in part, for the less sensitive to TLR stimulation. Therefore, the interplay of TLRs and TAM receptors could be important in the maintenance of immunological balance in the testis. We are collecting more evidence to confirm this hypothesis. It should be note that most of the studies on expression and function of TLRs in the testicular cells are performed in vitro using primary cells and purified ligands. Role of TLRs in defense against invading pathogens in the testis should be confirmed in vivo when animals are infected with microbes using TLR knockout mice.

\section{PARACRINE AND ENDOCRINE CYTOKINE REGULATION OF TESTICULAR INFLAMMATION}

Numerous paracrine and autocrine cytokines in the testis are critical for normal testicular functions. Most of these cytokines belong to immunoregulatory factors including those with immunosuppressive or pro-inflammatory activities, such as TGF- $\beta$ family (Avallet et al., 1994; O’Bryan et al., 2005). TGF- $\beta$ s contribute to testicular immune privilege through their immunosuppressive activities (Pollanen et al., 1993). TGF- $\beta 1$ facilitates SCs to support graft survival in co-transplantation experiments (Suarez-Pinzon et al., 2000).

Major pro-inflammatory factors, including IL-1, IL-6, and TNF- $\alpha$, are expressed in the testis and regulate testicular functions under physiological conditions. IL-1 is an important mediator of inflammation in the testis. A recent study showed that IL-1 $\alpha$ facilitates BTB opening by affecting the actin cytoskeleton (Sarkar et al., 2008). IL-1 $\beta$ is feebly produced by the testis under physiological conditions. However, an upregulation of IL-1 $\beta$ has been observed under inflammatory conditions in the testis, which may be harmful to spermatogenesis (Guazzone et al., 2009). IL-6 promotes potently inflammatory events via the expansion and activation of $\mathrm{T}$ cells. Most testicular cells, including somatic cells and germ cells in normal rats, produce IL-6 (Potashnik et al., 2005). IL-6 production is upregulated in LPS-induced acute testicular inflammation model. Moreover, IL-6 expression in testicular macrophages is significantly increased in EAO (Rival et al., 2006). Circulating monocytes $\left(\mathrm{ED}^{+}\right)$that arrive at the testis notably express IL- 6 at high levels compared with resident testicular macrophages $\left(\mathrm{ED}^{+}{ }^{+}\right)$, suggesting the distinct roles of the two types of macrophages in mediating inflammatory responses. An in vitro study has shown that exogenous IL-6 induces germ cell apoptosis (Theas et al., 2003). TNF- $\alpha$ is the most potent proinflammatory cytokine. TNF- $\alpha$ is prominently synthesized by germ cells within normal seminiferous tubules (De et al., 1993). Various types of interstitial cells, such as macrophages and mast cells, synthesize TNF- $\alpha$ (Xiong and Hales, 1993). TNF- $\alpha$ protects germ cells from apoptosis at a physiologically low concentrations in normal testes. In oppositely, TNF- $\alpha$ behaves as an apoptotic factor that induces germ cell death under inflammatory conditions (Theas et al., 2008). These three pro-inflammatory cytokines can be induced by TLR activation in testicular cells, including SCs, Leydig, and germ cells. Moreover, antiviral cytokines including IFN- $\alpha,-\beta$ are produced by these testis-specific cells through TLR activation (Wu et al., 2008; Sun et al., 2010; Shang et al., 2011; Wang et al., 2012). These cytokines could participate in the host defense against pathogens through the regulation of immune responses 
or the direct killing of invading pathogens in vivo. They may also impair spermatogenesis under the inflammatory conditions.

Various chemokines may regulate immune responses in the testis. Chemokines are a large family of small cytokines with chemoattractive activities. They can be grouped into the two major subfamilies, namely, CC ligands (CCLs) and CXC ligands (CXCLs). Among the CCL subfamilies, CCL2 (MCP-1) is present in the testis at physiologically low levels (Gerdprasert et al., 2002b). MCP- 1 is expressed by Leydig and MPCs and can be regulated by IL- 1, TNF- $\alpha$, and IFN- $\beta$. In response to TLR activation, MCP- 1 is upregulated in SCs (Riccioli et al., 2006). Injection of LPS in vivo induces elevated MCP-1 levels in the testicular fluid of rats (Gerdprasert et al., 2002b), increased MCP-1 levels have been observed in the testicular fluid of and EAO model (Guazzone et al., 2003). Among the CXCL subfamilies, CXCL10 is expressed in rat Leydig cells and upregulated by IL- $1 \alpha$, TNF- $\alpha$, and IFN- $\gamma$ (Hu et al., 1998). In addition, Sendai viruses induce CXCL1 and CXCL10 in rat testicular macrophages, SCs, Leydig cells, and MPCs (Aubry et al., 2000). Chemokines are not detected in rat germ cells. Increased chemokines could facilitate leukocyte infiltrations and promote the inflammatory reactions in the testis.

In contrast to inflammatory cytokines, IL-10, another antiflammatory cytokine, may reduce inflammation, autoimmunity, and spermatogenic damages in the mouse model of EAO (Watanabe et al., 2005). During inflammation, testicular resident macrophages produce IL-10. Production of immunosuppressive cytokines supports the speculation that testicular immune cells contribute to the testicular immune privileged status.

\section{CONCLUDING REMARIKS}

While the testis is a remarkable immune privileged site, chronic orchitis and autoimmunity are important etiological factors of

\section{REFERENCES}

Abe, M., Kurosawa, M., Ishikawa, O., Miyachi, Y., and Kido, H. (1998). Mast cell tryptase stimulates both human dermal fibroblast proliferation and type I collagen production. Clin. Exp. Allergy 28, 1509-1517.

Aguilar, R., Anton, F., Bellido, C., Aguilar, E., and Gaytan, F. (1995). Testicular serotonin is related to mast cells but not to Leydig cells in the rat. J. Endocrinol. 146, 15-21.

Allison, J., Georgiou, H. M., Strasser, A., and Vaux, D. L. (1997). Transgenic expression of CD95 ligand on islet beta cells induces a granulocytic infiltration but does not confer immune privilege upon islet allografts. Proc. Natl. Acad. Sci. U.S.A. 94, 3943-3947.

Andre, S., Tough, D. F., LacroixDesmazes, S., Kaveri, S. V., and Bayry, J. (2009). Surveillance of antigenpresenting cells by CD4+ CD25+ regulatory $\mathrm{T}$ cells in autoimmunity: immunopathogenesis and therapeutic implications. Am. J. Pathol. 174, 1575-1587.

Apa, D. D., Cayan, S., Polat, A., and Akbay, E. (2002). Mast cells

male infertility. Further investigation on the immunoregulation of the testis and the link between testicular inflammatory disorders and male infertility will have important implications for interventions of inflammatory disorder-related male infertility.

Mechanisms underlying testicular immune privilege remain largely misunderstood. A local innate immune system of the testis apparently plays an important role in the initiation of the testicular immune responses. Negative regulation of innate immunity in the testis must contribute to testicular immune privilege, which could be the focus of future research. TLR expression and function have recently been revealed in many testis-specific cells. These findings suggest that both immune cells and local tissue-specific cells possess innate immune protective roles against pathogens. Therefore, local cell-initiated inflammatory responses represent a topic that is worthy of further investigation. Endogenous TLR ligand-triggered non-infectious inflammatory conditions in the testis must be considered, because a large portion of spermatogenic cells undergo apoptosis under physiological and pathological conditions, which may release endogenous TLR ligands if the apoptotic cells are not removed timely. The manner by which systemic and local inflammations impair male fertility is another issue that remains unclear. Understanding of the fundamental aspects described above may provide novel insights into the development of prevention and treatment approaches for testicular inflammation-related male infertility.

\section{ACKNOWLEDGMENTS}

This work was supported by National Natural Science Foundation of China (Grant No. 30971459, 31171445) and Special Funds for Major State Basic Research Project of China (Grant No. 2007CB947504).

Bhushan, S., Tchatalbachev, S., Klug, J., Fijak, M., Pineau, C., Chakraborty, T., and Meinhardt, A. (2008). Uropathogenic Escherichia coli block MyD88-dependent and activate MyD88-independent signaling pathways in rat testicular cells. $J$. Immunol. 180, 5537-5547.

Biggiogera, M., Tanguay, R. M., Marin, R., Wu, Y., Martin, T. E., and Fakan, S. (1996). Localization of heat shock proteins in mouse male germ cells: an immunoelectron microscopical study. Exp. Cell Res. 229, 77-85.

Breucker, H. (1978). Macrophages, a normal component in seasonally involuting testes of the swan, Cygnus olor. Cell Tissue Res. 193, 463-471.

Brinster, R. L. (2002). Germline stem cell transplantation and transgenesis. Science 296, 2174-2176.

Chen, Y., Wang, H., Qi, N., Wu, H., Xiong, W., Ma, J., Lu, Q., and Han, D. (2009). Functions of TAM RTKs in regulating spermatogenesis and male fertility in mice. Reproduction 138, 655-666.

Cheng, X., Dai, H., Wan, N., Moore, Y., Vankayalapati, R., and Dai, Z. (2009).
Interaction of programmed death1 and programmed death-1 ligand1 contributes to testicular immune privilege. Transplantation 87,1778 1786.

Cohen, P. E., Nishimura, K., Zhu, L., and Pollard, J. W. (1999). Macrophages: important accessory cells for reproductive function. J. Leukoc. Biol. 66, 765-772.

Curtin, J. F., Liu, N., Candolfi, M., Xiong, W., Assi, H., Yagiz, K., Edwards, M. R., Michelsen, K. S., Kroeger, K. M., Liu, C., Muhammad, A. K., Clark, M. C., Arditi, M., Comin-Anduix, B., Ribas, A. Lowenstein, P. R., and Castro, M. G. (2009). HMGB1 mediates endogenous TLR2 activation and brain tumor regression. PLoS Med. 6, e10. doi: 10.1371/journal.pmed.1000010

Cutolo, M. (2009). Androgens in rheumatoid arthritis: when are they effectors? Arthritis Res. Ther. 11, 126. Cutolo, M., Sulli, A., Capellino, S., Villaggio, B., Montagna, P., Seriolo, B., and Straub, R. H. (2004). Sex hormones influence on the immune system: basic and clinical 
aspects in autoimmunity. Lupus 13, 635-638.

D’Alessio, A., Riccioli, A., Lauretti, P., Padula, F., Muciaccia, B., De Cesaris, P., Filippini, A., Nagata, S., and Ziparo, E. (2001). Testicular FasL is expressed by sperm cells. Proc. Natl. Acad. Sci. U.S.A. 98, 3316-3321.

Dai, Z., Nasr, I. W., Reel, M., Deng, S., Diggs, L., Larsen, C. P., Rothstein, D. M., and Lakkis, F. G. (2005). Impaired recall of CD8 memory $\mathrm{T}$ cells in immunologically privileged tissue. J. Immunol. 174, 1165-1170.

De, S. K., Chen, H. L., Pace, J. L., Hunt, J. S., Terranova, P. F., and Enders, G. C. (1993). Expression of tumor necrosis factor-alpha in mouse spermatogenic cells. Endocrinology 133, 389-396.

De Cesaris, P., Filippini, A., Cervelli, C., Riccioli, A., Muci, S., Starace, G., Stefanini, M., and Ziparo, E. (1992). Immunosuppressive molecules produced by Sertoli cells cultured in vitro: biological effects on lymphocytes. Biochem. Biophys. Res. Commun. 186, 1639-1646.

Dejucq, N., Lienard, M. O., Guillaume, E., Dorval, I., and Jegou, B. (1998). Expression of interferons-alpha and -gamma in testicular interstitial tissue and spermatogonia of the rat. Endocrinology 139, 3081-3087.

Dhein, J., Walczak, H., Baumler, C., Debatin, K. M., and Krammer, P. H. (1995). Autocrine T-cell suicide mediated by APO1/(Fas/CD95). Nature 373, 438-441.

Diemer, T., Hales, D. B., and Weidner, W. (2003). Immune-endocrine interactions and Leydig cell function: the role of cytokines. Andrologia 35, 55-63.

Duckett, R. J., Hedger, M. P., Mclachlan, R. I., and Wreford, N. G. (1997). The effects of gonadotropin-releasing hormone immunization and recombinant follicle-stimulating hormone on the Leydig cell and macrophage populations of the adult rat testis. J. Androl. 18, 417-423.

el-Demiry, M. I., Hargreave, T. B., Busuttil, A., Elton, R., James, K., and Chisholm, G. D. (1987). Immunocompetent cells in human testis in health and disease. Fertil. Steril. 48, 470-479.

Fijak, M., Bhushan, S., and Meinhardt, A. (2011). Immunoprivileged sites: the testis. Methods Mol. Biol. 677, 459-470.

Fijak, M., Iosub, R., Schneider, E., Linder, M., Respondek, K., Klug, J., and Meinhardt, A. (2005). Identification of immunodominant autoantigens in rat autoimmune orchitis. J. Pathol. 207, 127-138.
Fijak, M., and Meinhardt, A. (2006). The testis in immune privilege. Immunol. Rev. 213, 66-81.

Foulds, L. M., Boysen, R. I., Crane, M., Yang, Y., Muir, J. A., Smith A. I., De Kretser, D. M., Hearn, M. T., and Hedger, M. P. (2008). Molecular identification of lysoglycerophosphocholines as endogenous immunosuppressives in bovine and rat gonadal fluids. Biol. Reprod. 79, 525-536.

Frungieri, M. B., Calandra, R. S., Lustig, L., Meineke, V., Kohn, F. M., Vogt, H. J., and Mayerhofer, A. (2002a). Number, distribution pattern, and identification of macrophages in the testes of infertile men. Fertil. Steril. 78, 298-306.

Frungieri, M. B., Weidinger, S., Meineke, V., Köhn, F. M., and Mayerhofer, A. (2002b). Proliferative action of mast-cell tryptase is mediated by PAR2, COX2, prostaglandins, and PPARgamma: possible relevance to human fibrotic disorders. Proc. Natl. Acad. Sci. U.S.A. 99, 15072-15077.

Fujita, Y., Mihara, T., Okazaki, T., Shitanaka, M., Kushino, R., Ikeda, C., Negishi, H., Liu, Z., Richards, J. S., and Shimada, M. (2011). Toll-like receptors (TLR) 2 and 4 on human sperm recognize bacterial endotoxins and mediate apoptosis. Hum. Reprod. 26, 2799-2806.

Gaytan, F., Bellido, C., Aguilar, E., and Van Rooijen, N. (1994). Requirement for testicular macrophages in Leydig cell proliferation and differentiation during prepubertal development in rats. J. Reprod. Fertil. 102, 393-399.

Gerdprasert, O., O’Bryan, M. K., Muir, J. A., Caldwell, A. M., Schlatt, S., De Kretser, D. M., and Hedger, M. P. (2002a). The response of testicular leukocytes to lipopolysaccharideinduced inflammation: further evidence for heterogeneity of the testicular macrophage population. Cell Tissue Res. 308, 277-285.

Gerdprasert, O., O’Bryan, M. K., Nikolic-Paterson, D. J., Sebire, K., De Kretser, D. M., and Hedger, M. P. (2002b). Expression of monocyte chemoattractant protein-1 and macrophage colony-stimulating factor in normal and inflamed rat testis. Mol. Hum. Reprod. 8, 518-524.

Gold, S. M., and Voskuhl, R. R. (2009). Estrogen and testosterone therapies in multiple sclerosis. Prog. Brain Res. 175, 239-251.

Greenberg, S., and Grinstein, S. (2002). Phagocytosis and innate immunity. Curr. Opin. Immunol. 14, 136-145.

Guazzone, V. A., Jacobo, P., Theas, M. S., and Lustig, L. (2009). Cytokines and chemokines in testicular inflammation: a brief review. Microsc. Res. Tech. 72, 620-628.

Guazzone, V. A., Rival, C., Denduchis, B., and Lustig, L. (2003). Monocyte chemoattractant protein-1 (MCP1/CCL2) in experimental autoimmune orchitis. J. Reprod. Immunol. 60, 143-157.

Hafizi, S., and Dahlback, B. (2006). Signalling and functional diversity within the Axl subfamily of receptor tyrosine kinases. Cytokine Growth Factor Rev. 17, 295-304.

Haugen, T. B., Landmark, B. F., Josefsen, G. M., Hansson, V., and Hogset, A. (1994). The mature form of interleukin-1 alpha is constitutively expressed in immature male germ cells from rat. Mol. Cell. Endocrinol. 105, R19-23.

Head, J. R., and Billingham, R. E. (1985) Immune privilege in the testis. II. Evaluation of potential local factors. Transplantation 40, 269-275.

Head, J. R., Neaves, W. B., and Billingham, R. E. (1983). Immune privilege in the testis. I. Basic parameters of allograft survival. Transplantation 36, 423-431.

Hedger, M. P. (2002). Macrophages and the immune responsiveness of the testis. J. Reprod. Immunol. 57, 19-34. Hedger, M. P. (2011). Toll-like receptors and signalling in spermatogenesis and testicular responses to inflammation - a perspective. J. Reprod. Immunol. 88, 130-141.

Hedger, M. P., and Meinhardt, A. (2000). Local regulation of $\mathrm{T}$ cell numbers and lymphocyte-inhibiting activity in the interstitial tissue of the adult rat testis. J. Reprod. Immunol. $48,69-80$.

Hu, J., You, S., Li, W., Wang, D., Nagpal, M. L., Mi, Y., Liang, P., and Lin, T. (1998). Expression and regulation of interferon-gamma-inducible protein 10 gene in rat Leydig cells. Endocrinology 139, 3637-3645.

Hussein, M. R., Abou-Deif, E. S., Bedaiwy, M. A., Said, T. M., Mustafa, M. G., Nada, E., Ezat, A., and Agarwal, A. (2005). Phenotypic characterization of the immune and mast cell infiltrates in the human testis shows normal and abnormal spermatogenesis. Fertil. Steril. 83, 1447-1453.

Hutson, J. C. (2006). Physiologic interactions between macrophages and Leydig cells. Exp. Biol. Med. (Maywood) 231, 1-7.

Iosub, R., Klug, J., Fijak, M., Schneider, E., Frohlich, S., Blumbach, K., Wennemuth, G., Sommerhoff, C. P., Steinhoff, M., and Meinhardt, A. (2006). Development of testicular inflammation in the rat involves activation of proteinaseactivated receptor-2. J. Pathol. 208, 686-698.

Itoh, M., Terayama, H., Naito, M., Ogawa, Y., and Tainosho, S. (2005). Tissue microcircumstances for leukocytic infiltration into the testis and epididymis in mice. J. Reprod. Immunol. 67, 57-67.

Jacobo, P., Guazzone, V. A., JarazoDietrich, S., Theas, M. S., and Lustig, L. (2009). Differential changes in CD4+ and CD8+ effector and regulatory $\mathrm{T}$ lymphocyte subsets in the testis of rats undergoing autoimmune orchitis. J. Reprod. Immunol. 81, 44-54.

Jarow, J. P., Wright, W. W., Brown, T. R., Yan, X., and Zirkin, B. R. (2005). Bioactivity of androgens within the testes and serum of normal men. $J$. Androl. 26, 343-348.

Keir, M. E., Liang, S. C., Guleria, I., Latchman, Y. E., Qipo, A., Albacker, L. A., Koulmanda, M., Freeman, G. J., Sayegh, M. H., and Sharpe, A. H. (2006). Tissue expression of PD-L1 mediates peripheral $\mathrm{T}$ cell tolerance. J. Exp. Med. 203, 883-895.

Kern, S., and Maddocks, S. (1995). Indomethacin blocks the immunosuppressive activity of rat testicular macrophages cultured in vitro. J. Reprod. Immunol. 28, 189-201.

Kern, S., Robertson, S. A., Mau, V. J., and Maddocks, S. (1995). Cytokine secretion by macrophages in the rat testis. Biol. Reprod. 53, 1407-1416.

Korbutt, G. S., Suarez-Pinzon, W. L., Power, R. F., Rajotte, R. V., and Rabinovitch, A. (2000). Testicular Sertoli cells exert both protective and destructive effects on syngeneic islet grafts in non-obese diabetic mice. Diabetologia 43, 474-480.

Kuopio, T., Savouras, P. O., Pelliniemi, L. J., and Huhtaniemi, I. T. (1989). Transplantation of newborn rat testis under the kidney capsule of adult host as a model to study the structure and function of Leydig cells. $J$. Androl. 10, 335-345.

Le Tortorec, A., Denis, H., Satie, A. P., Patard, J. J., Ruffault, A., Jegou, B., and Dejucq-Rainsford, N. (2008). Antiviral responses of human Leydig cells to mumps virus infection or poly I:C stimulation. Hum. Reprod. 23, 2095-2103.

Lemke, G., and Rothlin, C. V. (2008). Immunobiology of the TAM receptors. Nat. Rev. Immunol. 8, 327-336.

Lu, Q., Gore, M., Zhang, Q., Camenisch, T., Boast, S., Casagranda, F., Lai, C., Skinner, M. K., Klein, R., Matsushima, G. K., Earp, H. S., Goff, S. P., and Lemke, G. (1999). Tyro-3 family receptors are essential regulators of 
mammalian spermatogenesis. Nature 398, 723-728.

Lustig, L., Lourtau, L., Perez, R., and Doncel, G. F. (1993). Phenotypic characterization of lymphocytic cell infiltrates into the testes of rats undergoing autoimmune orchitis. Int. J. Androl. 16, 279-284.

Ma, P., Ge, Y., Wang, S., Ma, J., Xue, S., and Han, D. (2004). Spermatogenesis following syngeneic testicular transplantation in Balb/c mice. Reproduction 128, 163-170.

Maekawa, M., Kamimura, K., and Nagano, T. (1996). Peritubular myoid cells in the testis: their structure and function. Arch. Histol. Cytol. 59, 1-13.

McCabe, M. J., Tarulli, G. A., Meachem, S. J., Robertson, D. M., Smooker, P. M., and Stanton, P. G. (2010). Gonadotropins regulate rat testicular tight junctions in vivo. Endocrinology 151, 2911-2922.

Meinhardt, A., Bacher, M., Metz, C., Bucala, R., Wreford, N., Lan, H., Atkins, R., and Hedger, M. (1998). Local regulation of macrophage subsets in the adult rat testis: examination of the roles of the seminiferous tubules, testosterone, and macrophage-migration inhibitory factor. Biol. Reprod. 59, 371-378.

Meinhardt, A., and Hedger, M. P. (2011). Immunological, paracrine and endocrine aspects of testicular immune privilege. Mol. Cell. Endocrinol. 335, 60-68.

Melaine, N., Lienard, M. O., Guillaume, E., Ruffault, A., DejucqRainsford, N., and Jegou, B. (2003). Production of the antiviral proteins 2'5'oligoadenylate synthetase, PKR and $\mathrm{Mx}$ in interstitial cells and spermatogonia. J. Reprod. Immunol. 59, 53-60.

Mellor, A. L., and Munn, D. H. (2006). Immune privilege: a recurrent theme in immunoregulation. Immunol. Rev. 213, 5-11.

Meng, J., Greenlee, A. R., Taub, C. J., and Braun, R. E. (2011). Sertoli cell-specific deletion of the androgen receptor compromises testicular immune privilege in mice. Biol. Reprod. 85, 254-260.

Meng, J., Holdcraft, R. W., Shima, J. E., Griswold, M. D., and Braun, R. E. (2005). Androgens regulate the permeability of the blood-testis barrier. Proc. Natl. Acad. Sci. U.S.A. 102, 16696-16700.

Millar, D. G., Garza, K. M., Odermatt, B., Elford, A. R., Ono, N., Li, Z., and Ohashi, P. S. (2003). Hsp70 promotes antigen-presenting cell function and converts T-cell tolerance to autoimmunity in vivo. Nat. Med. 9, 1469-1476.

Mital, P., Hinton, B. T., and Dufour, J. M. (2011). The blood-testis and blood-epididymis barriers are more than just their tight junctions. Biol. Reprod. 84, 851-858.

Nakanishi, Y., and Shiratsuchi, A. (2004). Phagocytic removal of apoptotic spermatogenic cells by Sertoli cells: mechanisms and consequences. Biol. Pharm. Bull. 27, 13-16.

Nasr, I. W., Wang, Y., Gao, G., Deng, S., Diggs, L., Rothstein, D. M., Tellides, G., Lakkis, F. G., and Dai, Z. (2005). Testicular immune privilege promotes transplantation tolerance by altering the balance between memory and regulatory $\mathrm{T}$ cells. $J$. Immunol. 174, 6161-6168.

O’Bryan, M. K., Gerdprasert, O., Nikolic-Paterson, D. J., Meinhardt, A., Muir, J. A., Foulds, L. M., Phillips, D. J., De Kretser, D. M., and Hedger, M. P. (2005). Cytokine profiles in the testes of rats treated with lipopolysaccharide reveal localized suppression of inflammatory responses. Am. J. Physiol. Regul. Integr. Comp. Physiol. 288, R1744-R1755.

Page, S. T., Plymate, S. R., Bremner, W. J., Matsumoto, A. M., Hess, D. L., Lin, D. W., Amory, J. K., Nelson, P. S., and Wu, J. D. (2006). Effect of medical castration on CD4+ CD25+ T cells, CD8+ T cell IFN-gamma expression, and NK cells: a physiological role for testosterone and/or its metabolites. Am. J. Physiol. Endocrinol. Metab. 290, E856-E863.

Pelletier, R. M., Yoon, S. R., Akpovi, C. D., Silvas, E., and Vitale, M. L. (2009). Defects in the regulatory clearance mechanisms favor the breakdown of self-tolerance during spontaneous autoimmune orchitis. Am. J. Physiol. Regul. Integr. Comp. Physiol. 296, R743-R762.

Pentikainen, V., Erkkila, K., Suomalainen, L., Otala, M., Pentikainen, M. O., Parvinen, M., and Dunkel, L. (2001). TNFalpha down-regulates the Fas ligand and inhibits germ cell apoptosis in the human testis. J. Clin. Endocrinol. Metab. 86, 4480-4488.

Piccinini, A. M., and Midwood, K. S. (2010). DAMPening inflammation by modulating TLR signalling. Mediat. Inflamm. 2010, 672395.

Pollanen, P., Von Euler, M., Jahnukainen, K., Saari, T., Parvinen, M., Sainio-Pollanen, S., and Soder, O. (1993). Role of transforming growth factor beta in testicular immunosuppression. J. Reprod. Immunol. 24, 123-137.

Potashnik, H., Elhija, M. A., Lunenfeld, E., Potashnik, G., Schlatt,
S., Nieschlag, E., and Huleihel, M. (2005). Interleukin-6 expression during normal maturation of the mouse testis. Eur. Cytokine Netw. 16, 161-165.

Raburn, D. J., Coquelin, A., Reinhart, A. J., and Hutson, J. C. (1993) Regulation of the macrophage population in postnatal rat testis. J. Reprod. Immunol. 24, 139-151.

Rettew, J. A., Huet-Hudson, Y. M. and Marriott, I. (2008). Testosterone reduces macrophage expression in the mouse of toll-like receptor 4, a trigger for inflammation and innate immunity. Biol. Reprod. 78, 432-437.

Riccioli, A., Starace, D., Galli, R., Fuso, A., Scarpa, S., Palombi, F., De Cesaris, P., Ziparo, E., and Filippini, A. (2006). Sertoli cells initiate testicular innate immune responses through TLR activation. J. Immunol. 177, 7122-7130.

Rival, C., Theas, M. S., Guazzone, V. A., and Lustig, L. (2006). Interleukin6 and IL-6 receptor cell expression in testis of rats with autoimmune orchitis. J. Reprod. Immunol. 70, 43-58.

Rival, C., Theas, M. S., Suescun, M. O., Jacobo, P., Guazzone, V., Van Rooijen, N., and Lustig, L. (2008). Functional and phenotypic characteristics of testicular macrophages in experimental autoimmune orchitis. J. Pathol. 215, 108-117.

Rothlin, C. V., Ghosh, S., Zuniga, E. I., Oldstone, M. B., and Lemke, G. (2007). TAM receptors are pleiotropic inhibitors of the innate immune response. Cell 131, 1124-1136.

Samy, E. T., Parker, L. A., Sharp, C. P., and Tung, K. S. (2005). Continuous control of autoimmune disease by antigen-dependent polyclonal $\mathrm{CD} 4+\mathrm{CD} 25+$ regulatory $\mathrm{T}$ cells in the regional lymph node. J. Exp. Med. 202, 771-781.

Sanberg, P. R., Borlongan, C. V., Saporta, S., and Cameron, D. F. (1996). Testisderived Sertoli cells survive and provide localized immunoprotection for xenografts in rat brain. Nat. Biotechnol. 14, 1692-1695.

Sanchez, J. F., Crooks, D. R., Lee, C. T., Schoen, C. J., Amable, R., Zeng, X., Florival-Victor, T., Morales, N., Truckenmiller, M. E., Smith, D. R., and Freed, W. J. (2006). GABAergic lineage differentiation of AF5 neural progenitor cells in vitro. Cell Tissue Res. 324, 1-8.

Sarkar, O., Mathur, P. P., Cheng, C. Y., and Mruk, D. D. (2008). Interleukin 1 alpha (IL1A) is a novel regulator of the blood-testis barrier in the rat. Biol. Reprod. 78, 445-454.
Schell, C., Albrecht, M., Mayer, C., Schwarzer, J. U., Frungieri, M. B., and Mayerhofer, A. (2008). Exploring human testicular peritubular cells: identification of secretory products and regulation by tumor necrosis factor-alpha. Endocrinology 149 , 1678-1686.

Schuppe, H. C., and Meinhardt, A. (2005). Immune privilege and inflammation of the testis. Chem. Immunol. Allergy 88, 1-14.

Schuppe, H. C., Meinhardt, A., Allam, J. P., Bergmann, M., Weidner, W., and Haidl, G. (2008). Chronic orchitis: a neglected cause of male infertility? Andrologia 40, 84-91.

Scott, H. M., Hutchison, G. R., Mahood, I. K., Hallmark, N., Welsh, M., De Gendt, K., Verhoeven, G., O'shaughnessy, P., and Sharpe, R. M. (2007). Role of androgens in fetal testis development and dysgenesis. Endocrinology 148, 2027-2036.

Selawry, H. P., and Cameron, D. F. (1993). Sertoli cell-enriched fractions in successful islet cell transplantation. Cell Transplant. 2, 123-129.

Seong, S. Y., and Matzinger, P. (2004). Hydrophobicity: an ancient damageassociated molecular pattern that initiates innate immune responses. Nat. Rev. Immunol. 4, 469-478.

Setchell, B. P. (1990). The testis and tissue transplantation: historical aspects. J. Reprod. Immunol. 18, 1-8.

Setchell, B. P., Granholm, T., and Ritzen, E. M. (1995). Failure of thyroid allografts to function in the testes of cynomolgous monkeys. J. Reprod. Immunol. 28, 75-80.

Shang, T., Zhang, X., Wang, T., Sun, B., Deng, T., and Han, D. (2011). Toll-like receptor-initiated testicular innate immune responses in mouse Leydig cells. Endocrinology 152, 2827-2836.

Simpson, E. (2006). A historical perspective on immunological privilege. Immunol. Rev. 213, 12-22.

Starace, D., Galli, R., Paone, A., De Cesaris, P., Filippini, A., Ziparo, E., and Riccioli, A. (2008). Toll-like receptor 3 activation induces antiviral immune responses in mouse sertoli cells. Biol. Reprod. 79, 766-775.

Statter, M. B., Foglia, R. P., Parks, D. E., and Donahoe, P. K. (1988). Fetal and postnatal testis shows immunoprivilege as donor tissue. J. Urol. 139, 204-210.

Su, L., Mruk, D. D., and Cheng, C. Y. (2011). Drug transporters, the blood-testis barrier, and spermatogenesis. J. Endocrinol. 208, 207-223.

Suarez-Pinzon, W., Korbutt, G. S., Power, R., Hooton, J., Rajotte, R. V., 
and Rabinovitch, A. (2000). Testicular sertoli cells protect islet beta-cells from autoimmune destruction in NOD mice by a transforming growth factor-betal-dependent mechanism. Diabetes 49, 1810-1818.

Suda, T., Takahashi, T., Golstein, P., and Nagata, S. (1993). Molecular cloning and expression of the Fas ligand, a novel member of the tumor necrosis factor family. Cell 75, 1169-1178.

Sun, B., Qi, N., Shang, T., Wu, H., Deng, T., and Han, D. (2010). Sertoli cellinitiated testicular innate immune response through toll-like receptor3 activation is negatively regulated by Tyro3, Axl, and mer receptors. Endocrinology 151, 2886-2897.

Takeda, K., and Akira, S. (2005). Tolllike receptors in innate immunity. Int. Immunol. 17, 1-14.

Takeda, Y., Gotoh, M., Dono, K., Nishihara, M., Grochowiecki, T., Kimura, F., Yoshida, T., Ohta, Y., Ota, H., Ohzato, H., Umeshita, K., Takeda, T., Matsuura, N., Sakon, M., Kayagaki, N., Yagita, H., Okumura, K., Miyasaka, M., and Monden, M. (1998). Protection of islet allografts transplanted together with Fas ligand expressing testicular allografts. Diabetologia 41, 315-321.

Tao, W., Xiaoyan, Z., Qiaoyuan, C., Tingting, D., Yue, Z., Nan, L., Tao, S., Yongmei, C., and Daishu, H. (2012). Toll-like receptor 3-initiated antiviral responses in mouse male germ cells in vitro. Biol. Reprod. 86, 1-10.

Theas, M. S., Rival, C., Jarazo-Dietrich, S., Jacobo, P., Guazzone, V. A., and Lustig, L. (2008). Tumour necrosis factor-alpha released by testicular macrophages induces apoptosis of germ cells in autoimmune orchitis. Hum. Reprod. 23, 1865-1872.

Theas, S., Rival, C., and Lustig, L. (2003). Germ cell apoptosis in autoimmune orchitis: involvement of the Fas-FasL system. Am. J. Reprod. Immunol. 50, 166-176.

Tung, K. S., Teuscher, C., and Meng, A. L. (1981). Autoimmunity to spermatozoa and the testis. Immunol. Rev. 55, 217-255.

Vabulas, R. M., Ahmad-Nejad, P., Da Costa, C., Miethke, T., Kirschning, C. J., Hacker, H., and Wagner, H. (2001). Endocytosed HSP60s use toll-like receptor 2 (TLR2) and TLR4 to activate the toll/interleukin1 receptor signaling pathway in innate immune cells. J. Biol. Chem. 276, 31332-31339.

Verhoeven, G., Hoeben, E., and De Gendt, K. (2000). Peritubular cell-Sertoli cell interactions: factors involved in PmodS activity. Andrologia 32, 42-45.

Wang, H., Chen, Y., Ge, Y., Ma, P., Ma, Q., Ma, J., Xue, S., and Han, D. (2005). Immunoexpression of Tyro 3 family receptors - Tyro 3, Axl, and Mer - and their ligand Gas6 in postnatal developing mouse testis. J. Histochem. Cytochem. 53, 1355-1364.

Wang, T., Zhang, X., Chen, Q., Deng, T., Zhang, Y., Li, N., Shang, T., Chen, Y., and Han, D. (2012). Toll-like receptor 3-initiated antiviral responses in mouse male germ cells in vitro. Biol. Reprod. 86, 1-10.

Watanabe, M., Kashiwakura, Y., Kusumi, N., Tamayose, K., Nasu, Y., Nagai, A., Shimada, T., Daida, H., and Kumon, H. (2005). Adeno-associated virus-mediated human IL-10 gene transfer suppresses the development of experimental autoimmune orchitis. Gene Ther. 12, 1126-1132.

Wheeler, D. S., Chase, M. A., Senft, A. P., Poynter, S. E., Wong, H. R., and Page, K. (2009). Extracellular Hsp72, an endogenous DAMP, is released by virally infected airway epithelial cells and activates neutrophils via Toll-like receptor (TLR)-4. Respir. Res. 10, 31. Wheeler, K., Tardif, S., Rival, C., Luu, B., Bui, E., Del Rio, R., Teuscher, C., Sparwasser, T., Hardy, D., and Tung, K. S. (2011). Regulatory T cells control tolerogenic versus autoimmune response to sperm in vasectomy. Proc. Natl. Acad. Sci. U.S.A. 108 7511-7516.

Winnall, W. R., Muir, J. A., and Hedger, M. P. (2011). Differential responses of epithelial Sertoli cells of the rat testis to Toll-like receptor 2 and 4 ligands: implications for studies of testicular inflammation using bacterial lipopolysaccharides. Innate Immun. 17, 123-136.

Wu, H., Wang, H., Xiong, W., Chen, S., Tang, H., and Han, D. (2008). Expression patterns and functions of toll-like receptors in mouse sertoli cells. Endocrinology 149, 4402-4412.

Wyatt, C. R., Law, L., Magnuson, J. A. Griswold, M. D., and Magnuson, N. S. (1988). Suppression of lymphocyte proliferation by proteins secreted by cultured Sertoli cells. J. Reprod. Immunol. 14, 27-40.

Xiong, Y., and Hales, D. B. (1993). Expression, regulation, and production of tumor necrosis factoralpha in mouse testicular interstitial macrophages in vitro. Endocrinology 133, 2568-2573.
Yule, T. D., Montoya, G. D., Russell, L. D., Williams, T. M., and Tung, K. S. (1988). Autoantigenic germ cells exist outside the blood testis barrier. J. Immunol. 141, 1161-1167.

Zetterstrom, C. K., Strand, M. L., and Soder, O. (2006). The high mobility group box chromosomal protein 1 is expressed in the human and rat testis where it may function as an antibacterial factor. Hum. Reprod. 21 , 2801-2809.

Conflict of Interest Statement: The authors declare that the research was conducted in the absence of any commercial or financial relationships that could be construed as a potential conflict of interest.

Received: 08 March 2012; paper pending published: 23 March 2012; accepted: 23 May 2012; published online: 11 June 2012.

Citation: Li N, Wang $T$ and Han D (2012) Structural, cellular and molecular aspects of immune privilege in the testis. Front. Immun. 3:152. doi: 10.3389/ fimmu.2012.00152

This article was submitted to Frontiers in Immunological Tolerance, a specialty of Frontiers in Immunology.

Copyright (c) $2012 \mathrm{Li}$, Wang and Han. This is an open-access article distributed under the terms of the Creative Commons Attribution Non Commercial License, which permits non-commercial use, distribution, and reproduction in other forums, provided the original authors and source are credited. 